\title{
Epilepsy in a Longitudinal Survey of 5,000 Children*
}

\author{
J. E. COOPER,† B.M., B.CH., M.R.C.P., D.P.M.
}

Brit. med. F., 1965, 1, 1020-1022

This paper records some of the findings concerning different types of epilepsy in a longitudinal study of approximately 5,000 children born in 1946. These children form the National Survey of Health and Development which has been described previously (Douglas and Rowntree, 1948 ; Douglas and Blomfield, 1956). The children are drawn from all parts of Great Britain and from all social classes, and have been kept under observation from their birth in March 1946 to the present. Apart from death and emigration, losses from the survey have been small, and at the age of 15 years were approximately $10 \%$ (for details of the survey method and losses see Douglas and Blomfield (1958), and Douglas (1964)).

During the 18 years of their lives a large amount of social, medical, and educational information has been gathered about each child, and the medical information referred to in this paper comes mainly from : (1) A home visit by a health visitor when the child was aged 2 years. The mother was asked if the child had ever had any sort of fit or convulsion, and if so, at what age and how many. She was also asked in detail about illnesses such as whooping-cough, measles, ear disease, chicken-pox, gastro-enteritis, and lower respiratory infections. (2) Medical examinations carried out specially for this survey by school medical officers at the ages of $6,7,11$, and 15 . The mothers, who accompanied the children, were asked if their child had had any sort of fits or convulsions in the previous year, and if so, how many and whether they had accompanied any other illness.

In this report the definition of " a fit" is a definite reply of "yes" recorded by the doctor or the health visitor after asking these questions. The doctor was at liberty to ask other questions to clarify the mother's reply, and the extent of additional probing would obviously vary. In a widespread survey such as this, however, there was no way of avoiding this sort of variation.

It is thus possible to record for these children the incidence of fits in the first two years, and at the ages of $6,7,11$, and 15 the overall prevalence of fits, and the inception rate of new fits in the previous year.

\section{Findings}

Table I shows the prevalence and inception rates of all kinds of fits at the ages of $2,6,7,11$, and 15 years. The rate for fits in those under 2 years is clearly the most reliable of these, since it is based upon over 100 children. There are not many other figures from this country with which these rates can be compared, and Pond, Bidwell, and Stein's (1960) survey of general practice is probably the nearest equivalent. Our rate of 22.7 per thousand among children surviving to the age of 2 years is close to their rate of 19.9 per thousand. McDonald's (1961) survey in Watford found 40 per thousand with fits in the first five years, but a comparable figure cannot be calculated from our survey owing to the gap in information between 2 and 6 years. (A rough estimate suggests that it is unlikely that our rate would have been more than 30 per

\footnotetext{
* Based on a paper read on 13 March 1964 at the Annual Meeting of the British Branch of the International League against Epilepsy.

t Medical Research Council Unit for the Study of Environmental Factors in Mental and Physical Illness, London School of Economics, London.
}

thousand over the first five years.) The rates at the ages of $6,7,11$, and 15 are not exactly comparable with other studies reported, but are obviously of the same order of size as the rates for the larger age groupings given in Pond's survey, although again ours are slightly larger.

TABLE I.-Prevalence and Inception Rate of Fits at Ages 2, 6, 7, 11, and
15 (Rates Are Inflated Up to the Original Sample Size: Numbers Are the Actual Numbers of Children Studied)

\begin{tabular}{|c|c|c|c|c|}
\hline $\begin{array}{l}\text { Age Examined } \\
\text { (and No. of Children) }\end{array}$ & $\begin{array}{l}\text { No. with } \\
\text { Fits }\end{array}$ & $\begin{array}{c}\text { Total } \\
\text { Prevalence } \\
\text { (per 1,000) }\end{array}$ & $\begin{array}{l}\text { Old Cases } \\
\text { (per } 1,000)\end{array}$ & $\begin{array}{l}\text { New Cases } \\
\text { (per 1,000) }\end{array}$ \\
\hline $\begin{array}{lll}2 \text { years }(4,779) & \ldots & \ldots \\
6 \text { years }(4,221) & \ldots & \ldots \\
7 \text { years }(4,094) & \ldots & \ldots \\
11 \text { years }(3,934) & & \ldots \\
15 \text { years }(3,698) & & \ldots\end{array}$ & $\begin{array}{r}107 \\
34 \\
21 \\
23 \\
27\end{array}$ & $\begin{array}{r}22 \cdot 7 \\
8 \cdot 2 \\
4 \cdot 3 \\
7 \cdot 1 \\
8 \cdot 2\end{array}$ & $\begin{array}{l}\overline{2 \cdot 6} \\
2 \cdot 8 \\
3 \cdot 4 \\
4 \cdot 7\end{array}$ & $\begin{array}{l}5 \cdot- \\
5 \cdot 6 \\
1 \cdot 5 \\
3 \cdot 7 \\
3 \cdot 5\end{array}$ \\
\hline
\end{tabular}

For the purposes of discussion these children have been divided into the following groups : (1) deaths associated with fits (13); (2) children with fits before the age of 2 (107), either without an accompanying illness (74) or with an accompanying illness (33); (3) children with fits after the age of 2 , but on one occasion only (28); (4) children with several fits after the age of 2 (26); and (5) children with petit mal (15).

\section{Deaths Associated with Fits}

Detailed medical information on the circumstances of the very early deaths in the survey is not available, so reliable rates for all deaths in which fits occurred in the first two years cannot be quoted. For completeness, however, the 13 children at whose deaths fits occurred are described here briefly. In nine of these death was not due to the fits themselves but to some other severe illness such as whoopingcough with pneumonia, meningitis, gastro-enteritis, or multiple congenital defects. Of the other four children, one died at 3 days with convulsions said to be caused by severe toxaemia of pregnancy ; two died with many convulsions called "idiopathic" at the age of 4 months and 11 months; and one imbecile child died in status epilepticus aged 7 years. (Twelve of these deaths took place in the first two years, so the fits occurring in this period can be expressed as a total prevalence of 24.8 per thousand in the original survey population, or as a prevalence rate of 22.7 per thousand in those surviving at the age of 2 years.)

\section{Children with Fits Under the Age of 2 Years}

These have been subdivided into 74 who had a fit or a group of fits for no obvious reason, and 33 who had a fit during the course of an illness such as whooping-cough, gastro-enteritis, pneumonia, measles, or meningitis. Remarks on the history forms such as "teething" or "? cold" were not counted as definite illnesses.

The Newcastle study (Miller, Court, Walton, and Knox, 1960) would lead one to expect that the children without an obvious cause for their fits would come from lower social groups and from families with poor standards of care, when compared with those with an obvious precipitating cause for the fits. In the National Survey, however, there is a slight 
excess from the upper social groups in the children with fits without illness. However, examination of the ratings for standard of maternal care and housing shows that, in spite of this, more of these children without an obvious cause for their fits come from homes rated poorly for standard of care when compared with the other group. This excess is not large, but it agrees with the Newcastle study in essence.

The times of onset of these fits are spread over the first two years, falling off in the last three months. This survey is not large enough to produce a significant number of children with brain damage due to birth trauma who might be expected to have fits immediately and have a high post-natal death rate.

\section{Children Having their First and Only Fit After the Age of 2}

There are 28 in this group, with an unexpected preponderance of girls (18 girls, 10 boys); when allowance is made for the original sampling, there are more than twice as many girls as boys. Two possible sources of the over-reporting of fits in girls have to be examined to see if this odd finding can be explained. The excess of girls might be due to the misreporting of faints or "turns" around the start of menstruation, but examination of the individual records shows this is not the case. It could, however, be connected with the high rate of maladjustment in the group: for 6 of the 18 , girls and 4 of the 10 boys were rated as severely maladjusted by their teachers, which is roughly three times the expected rate. These girls are mainly from the manual-working class, which agrees with the known high rate of maladjustment among working-class girls in this survey (Mulligan, 1964). It may be that maladjusted children have more fits than other children, or they may merely have faints, outbursts, or "turns" which are misreported as fits. (An illness was reported to have accompanied the fit in 13 of these 28 children, but this was not associated with either the presence or absence of maladjustment.)

\section{Children with Fits on Several Occasions After the Age of 2 Years}

This group contains what might be called the proper epileptics-there are 26, three of whom are known to be spastics (21 of them attended normal schools). There are rather more girls than boys, but not significantly so. None of these children were recorded as having major fits more than monthly, and most of them had just one or two a year, often missing a year of the four reported. The only two children recorded as habitually having more than one seizure a week had both petit mal and grand mal.

This group of 26 children with more than one fit is not large enough to allow a more detailed analysis of social and environmental information, but simple inspection of their social class, and ratings for maternal care and housing does not show any particular deviations. They are also normally distributed when their school performance and maladjustment ratings are examined.

\section{Children with Petit Mal}

Fifteen were reported as having petit mal seizures, three of these having major seizures also. The 12 with petit mal appeared in the records only from the age of 6 onwards, as might be expected.

\section{Relation Between Infantile and Later Fits}

This survey emphasizes that children having fits before the age of 2 are not necessarily those who have fits later. Of the
107 with fits before the age of 2 , only six had fits at the age of 6 years, and three of these six had no more after this. Although the period between 2 and 6 years is not systematically covered, we know of eight more children who had a fit some time between the ages of 2 and 4 years, and one at 5 years, but none of these had any fits later.

Looking at this from the other end, of the 20 children with several fits at the age of 6 or later, only three had had infantile convulsions. These three children seem to be unusual in other ways-one had a congenital heart lesion and has had gastro-enteritis and pneumonia twice, one has a spastic right leg, and the third had pyloric stenosis. Similarly, none of the 12 children with uncomplicated petit mal had fits before 2 years.

\section{Fits and Birth Order}

The birth order of these children is known, and so the proportion of firstborn with fits can be compared with the proportion of firstborn in the whole group. The children with fits of any sort contain slightly fewer firstborn than expected $-38 \%$ against $41 \%$-which is due to a slight excess of younger children from large families among the infantile convulsions group-but these are insignificant differences.

Taking just those with several fits after the age of 2 , exactly the expected proportion of firstborn is found- $41 \%$. This is only a small group of 26 , however, and contains very few children with brain damage or frequent severe fits, so this finding is not necessarily applicable, for instance, to a highly selected hospital population of severe epileptics.

\section{Low Birth Weight}

There is a slight excess of premature children-that is, with a birth weight of less than $5 \frac{1}{2} \mathrm{lb}$. $(2.5 \mathrm{~kg}$.)-when all those with fits are taken together (12 out of 164 survivors, which is $7 \%$ compared with $4 \%$ of surviving premature children in the whole survey). This excess is derived from the children with several fits after the age of 2 years (26 children, five of whom were premature).

Only 5 of the 107 children who had fits before the age of 2 years but not later were premature, which is the expected number.

\section{Performance of these Children at School}

One of the main aims of the National Survey has been to follow these children through their school careers, and a great deal of information on their work, behaviour, and achievement at school has been collected-a book on the relations between school achievement, home conditions, standards of teaching, and parental concern has iust been published (Douglas, 1964).

Analysis of this educational information is still going on, but it seemed worth while to take some of the school performance records already available to see if these children with fits differ from the rest. The "test scores" referred to are derived from batteries of tests given at the age of 8,11 , and 15 , with the advice and help of the National Foundation for Educational Research in England and Wales, and can be regarded as summaries of the child's performance at school. These test scores can be shown to be affected by environmental influences as well as innate abilities, the most potent factors being social class, level of parental interest in school progress, standard of housing, and size of family. Before the school test scores of children grouped by some other criterion can be compared allowance has to be made for these influences, and this has been done in the test scores given in 
Tables II and III. (The scores are also standardized to give a meant of 50 and a standard deviation of 10.)

TABLE II.-Children with Major Fit(s) at Any Time (Excluding Brain Damage and Petit Mal). Number of Children in School Test Score Groups: Expected Numbers in Parentheses

\begin{tabular}{|c|c|c|c|c|c|c|c|}
\hline \multirow{2}{*}{ Year } & \multirow{2}{*}{ Age } & \multicolumn{5}{|c|}{ Test Score Groups } & \multirow{2}{*}{ Total } \\
\hline & & $0-40$ & 41-45 & $46-54$ & $55-59$ & $60-99$ & \\
\hline $\begin{array}{l}1954 \\
1957 \\
1961\end{array}$ & $\begin{array}{r}8 \\
11 \\
15\end{array}$ & $\begin{array}{l}25(20) \\
17(19) \\
24(19)\end{array}$ & $\begin{array}{l}29(22) \\
22(21) \\
21(22)\end{array}$ & $\begin{array}{l}50(51) \\
50(49) \\
49(50)\end{array}$ & $\begin{array}{l}17(21) \\
22(20) \\
22(20)\end{array}$ & $\begin{array}{l}10(17) \\
14(16) \\
11(16)\end{array}$ & $\begin{array}{l}131 \\
125 \\
127\end{array}$ \\
\hline
\end{tabular}

TABLE III.-Children with Major Fit(s) at Any Time (Excluding Brain Damage and Petit Mal). Number of Children in School Test Score Groups Aged 8 Years: Expected Numbers in Parentheses

\begin{tabular}{|c|c|c|c|c|}
\hline & \multicolumn{3}{|c|}{ Test Score Group Aged 8 Years } & \multirow{2}{*}{ Total } \\
\hline & $0-45$ & $45-54$ & $55-59$ & \\
\hline Fit(s) before 2 years $\left\{\begin{array}{l}\text { No illness } \\
\text { With illness* }\end{array}\right.$ & $\begin{array}{l}19(19) \\
14(8)\end{array}$ & $\begin{array}{r}26(23) \\
5(11)\end{array}$ & $\begin{array}{r}13(16) \\
7(7)\end{array}$ & $\begin{array}{l}58 \\
26\end{array}$ \\
\hline Fit(s) after 2 years $\left\{\begin{array}{l}\text { Only } 1 \text { fit } \\
\text { Many fits }\end{array}\right.$ & $\begin{array}{rr}14 & (9) \\
7 & (6)\end{array}$ & $\begin{aligned} 9(11) \\
10(8)\end{aligned}$ & $\begin{array}{ll}4 & (7) \\
3 & (6)\end{array}$ & $\begin{array}{l}27 \\
20\end{array}$ \\
\hline
\end{tabular}

$\chi^{2}=7 \cdot 77$, with 2 D.F., $0.05>\mathrm{P}>0.02$

$\chi^{2}=7 \cdot 77$, with 2 D.F.,
$+\chi^{2}=4 \cdot 05>$, with 2 D.F., $P>0.05$

The school test scores were not available for 14, 23, and 18 children at the ages of 8,11 , and 15 respectively. The 12 children with petit mal only, and the seven with spasticity or other cerebral abnormalities, have not been included in these tables, since they are too few in number to be considered separately, and the different nature of their abnormalities makes inclusion with the other groups unjustified. (The score distributions of the 12 children with petit mal only came close to a normal distribution on all three occasions. All seven of the other group were more than 1 standard deviation below the mean, this group being composed of two children with spastic diplegia, four with spastic hemiplegia, and one child with a small occipital meningocele.)

This leaves 131, 125, and 127 children at the three test occasions whose scores are shown in Table II. The expected numbers shown in parentheses indicate how many children would be expected in the test-score intervals out of a group the same size as the epileptic group in question, having the same social class composition, and with similar rating for size of family, standard of housing, and level of parental interest in school. In Table II there is an excess of children in the average and below-average groups at the age of 8 , and Table III shows that this is accounted for partly by the children who had fits under the age of 2 years with an accompanying illness, and partly by those who had only one fit or group of fits after the age of 2 .

The explanation of the low school achievement of the children with only one fit or group of fits after the age of 2 probably lies in the excess of maladjusted children in this group already noted, for ratings of severe maladjustment tend to go with poor school achievement (Mulligan, 1964).

The poor achievement of the children who had fits before the age of 2 with an accompanying illness is unexpected and less easy to explain. To examine the effect of a severe illness without an accompanying fit the school test scores were examined of 40 children who had been in hospital for the same sort of illnesses (whooping-cough, gastro-enteritis, measles, pneumonia), but their distribution was quite normal. There are slightly more moderately maladjusted children in this group than expected, but nothing like enough to explain the whole effect. It would be unwise to make too much of this finding, for these children had caught up with the rest of the survey children at the ages of 11 and 15 , and it is in any case a small group (26). This point cannot be pursued in any more detail in this survey, but further investigation of such children elsewhere would be of interest.

\section{Summary}

The prevalence and inception rates of reported fits are described at the ages of $2,5,7,11$, and 15 years in a longitudinal survey of approximately 5,000 children (National Survey of Health and Development). The most reliable finding was a rate of 22.7 children per thousand having any sort of fit among those surviving to the age of 2 years.

Subdivision of those children who had a fit before the age of 2 years according to the presence or absence of an obvious precipitating cause showed that although there was little social class difference, more of the children without an obvious cause for their fits came from homes rated poorly for standards of parental care and interest when compared with those whose fits accompanied an obvious illness.

There was an excess of maladjusted working-class girls among the 28 children reported as having their first and only fit after the age of 2 years.

Most of the 26 children who had fits on several occasions after the age of 2 years had only one or two fits a year, and the only two children recorded as habitually having more than one seizure a week had both petit mal and grand mal. There was no relation between birth order and the occurrence of fits, but there was an excess of premature children in the group with repeated fits after the age of 2 .

The 26 children with fits after the age of 2 years were not derived from the 107 who had had fits before the age of 2 , except for three children who also had other abnormalities.

Examination of special-school test scores showed that at the age of 6 years those children who had had fits with an obvious illness before the age of 2 did less well than expected, but this effect was less marked at the ages of 11 and 15 .

I am grateful to Dr. J. W. B. Douglas, Director of the National Survey of Health and Development, for advice and encouragement, and for access to the school test scores.

The National Survey of Child Health and Development was sponsored by a joint committee of the Institute of Child Health, the Society of Medical Officers of Health, and the Population Investigation Committee. It is now being directed from the Medical Research Council Unit at the London School of Economics. In its early years the inquiry was financed by the Nuffield Foundation, and grants for continuing it through the school years have come from many sources, including the Ford Foundation and the Population Council, Inc.

This study was possible only because of the generous help given by medical officers of health, school medical officers, health visitors, directors of education, school nurses, and teachers in all parts of Great Britain. We should also like to thank the mothers who willingly answered numerous detailed questions, and their children who were on four occasions examined by the school medical officcrs.

\section{REFERENCES}

Douglas, J. W. B. (1964). The Home and the School. MacGibbon \& Kee, Aldershot, Hampshire.

and Blomfield, J. M. (1956). Milbank mem. Fd Quart., 34, 227. and Blomfield, J. M. (1956). Milbank mem. Fd Quart., 34, 227 and Rowntree, G. (1948). Maternity in Great Britain. Oxford and Rowntree, G. (1948).

McDonald, A. D. (1961). Brit. F. prev. soc. Med., 15, 154

Miller, F. J. W., Court, S. D. M., Walton, W. S., and Knox, E. G. (1960). Growing up in Newcastle on Tyne." Oxford University Press, London.

Mulligan, G. (1964). Ph.D. Thesis. London University.

Pond, D. A. Bidwell, B. H., and Stein, L. (1960). Psychiat. Neurol. Neurochir. (Amst.), 63, 217. 